\section{AGING REDUCES POSTISCHEMIC RECOVERY OF CORONARY ENDOTHELIAL FUNCTION}

The aging process is known to be associated with profound changes in the heart. To determine whether resistance of coronary endothelial and vascular smooth muscle function to ischemia may be related to age, four groups of rats ( $n=6$ in each group) of different ages $(1,5,15$, and 26 months) were subjected to cardioplegic arrest for 4 hours at $4^{\circ} \mathrm{C}$. The postischemic basal release of nitric oxide by endothelium, as assessed by the percentage loss of coronary flow in response to $0.5 \mathrm{mmol} / \mathrm{L} \mathrm{L}$-monomethylarginine, an inhibitor of nitric oxide synthase, was as follows: (mean \pm standard error of the mean): $87.1 \% \pm 1.7 \%, 81.2 \% \pm 2.3 \%, 79.6 \% \pm 1.9 \%$, and $74.9 \% \pm 2.4 \%$ in groups $1,2,3$, and 4 , respectively. Stimulated release of nitric oxide, as assessed by percentage increase of coronary flow to $10^{-5} \mathrm{mmol} / \mathrm{L} \mathrm{5}$-hydroxytryptamine, an endothelium-dependent vasodilator, was as follows (mean \pm standard error of the mean): $88.3 \% \pm 1.5 \%, 83.4 \% \pm 2.4 \%$, $71.1 \% \pm 2.7 \%$, and $63.1 \% \pm 3.3 \%$ in groups $1,2,3$, and 4 , respectively. Significant differences were found between each group $(p<0.05)$ for both basal and stimulated release of nitric oxide. Vascular smooth muscle function, as assessed by the percentage increase in coronary flow in response to glyceryl trinitrate, an endothelium-independent vasodilator, was (mean \pm standard error of the mean): $96.7 \% \pm 2.1 \%, 92.3 \% \pm 5.2 \%$, $\mathbf{9 2 . 9 \%} \pm \mathbf{5 . 0 \%}$, and $98.1 \% \pm 2.4 \%$ in groups $1,2,3$, and 4 respectively. No significant difference was found between groups ( $p=$ not significant). In a protocol mimicking conditions for transplantation, the postischemic recovery of the basal and stimulated release of nitric oxide, but not vascular smooth muscle function, diminished with age. (J THORAC CARDIOVASC SURG $1996 ; 111: 238-45$ )

Mohamed Amrani, MD, Adrian H. Chester, PhD, Jay Jayakumar, MB, and Magdi H. Yacoub, FRCS, Harefield, United Kingdom
$T_{\text {the }}^{\text {he }}$ he aging process is known to elicit chemical and functional changes in the heart. ${ }^{1}$ These changes can affect one or more of the cellular components. Cardiac contractility, that is, myocardial function, is known to show differential vulnerability to ischemia with aging. ${ }^{2}$ This change could be related to metabolic, physiologic, and ultrastructural alterations that accompany the aging process. ${ }^{3-7}$

Coronary endothelium constitutes a complex dy-

From the Department of Cardiothoracic Surgery, National Heart and Lung Institute, Harefield Hospital, Harefield, United Kingdom.

Received for publication Feb. 16, 1995.

Accepted for publication May 18, 1995.

Address for reprints: Magdi H. Yacoub, FRCS, FRCP, DSc, Department of Cardiac Surgery, Harefield Hospital and NHLI, Harefield, Middlesex UB9 6JH, United Kingdom.

Copyright $(1996$ by Mosby-Year Book, Inc.

$0022-5223 / 96 \$ 5.00+0 \quad \mathbf{1 2} / \mathbf{1} / \mathbf{6 6 3 3 0}$ namic organ with diverse functions, which include the synthesis and release of vasoactive substances. ${ }^{8}$ Basal secretion of one of these substances, nitric oxide, ${ }^{9}$ has been shown to be essential for maintenance of coronary tone and mechanical function. ${ }^{10}$ Although this emphasizes the need to integrate factors influencing coronary tone in the strategy of myocardial preservation, little is known about the influence of age on the capacity of endothelial function (EF) for recovery after ischemia. The purpose of this study was to investigate the influence of age on the recovery of basal and stimulated release of nitric oxide by the endothelium after prolonged cardioplegic arrest.

\section{Materials and methods}

Animals. Male Sprague-Dawley rats were used in all experiments. Six hearts were studied in each group. In all studies, animals received humane care in compliance with the "Principles of Laboratory Animal Care" formulated 


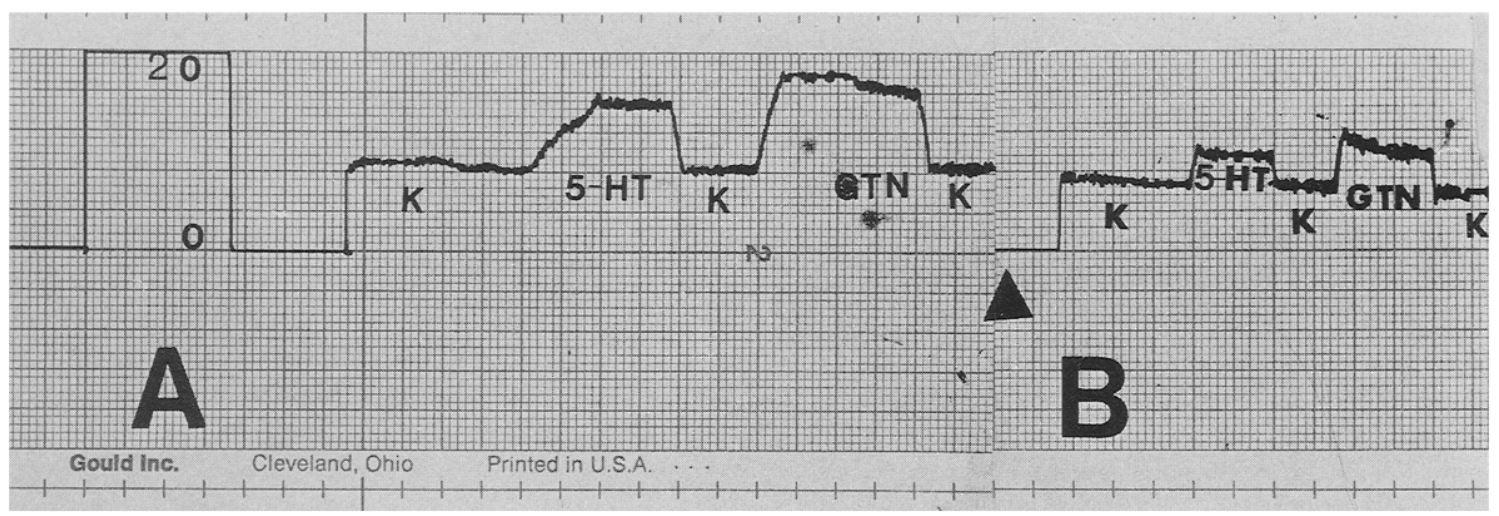

Fig. 1. Experimental time course. Analog tracing showing the sequence of perfusion and the variation of coronary flow $(\mathrm{ml} / \mathrm{L})$ before $(A)$ and $\operatorname{after}(B)$ ischemia. $K$, Krebs solution. Triangle represents onset of cardioplegic arrest.

by the National Society for Medical Research and the "Guide for the Care and Use of Laboratory Animals" prepared by the Institute of Laboratory Animal Resources and published by the National Institutes of Health (NIH publication No. 80-23, revised 1978). Animals were chosen from four age groups: group 1, 1 month; group 2, 5 months; group 3, 15 months; and group 4, 26 months.

Experimental preparation. The isolated rat heart preparation used in this study has already been described in detail elsewhere. ${ }^{11}$ Briefly, in this preparation of the left side of the heart oxygenated Krebs-Henseleit bicarbonate buffer $(118 \mathrm{mmol} / \mathrm{L}$ sodium chloride, $25 \mathrm{mmol} / \mathrm{L}$ sodium bicarbonate, $4.75 \mathrm{mmol} / \mathrm{L}$ potassium chloride, $1.19 \mathrm{mmol} / \mathrm{L}$ magnesium sulfate, $1.18 \mathrm{mmol} / \mathrm{L}$ potassium phosphate, and $2.5 \mathrm{mmol} / \mathrm{L}$ calcium chloride), $\mathrm{pH} \mathrm{7.4,}$ containing $11.1 \mathrm{mmol} / \mathrm{L}$ glucose and gassed with $95 \%$ oxygen and $5 \%$ carbon dioxide at $37^{\circ} \mathrm{C}$, flows from a reservoir $100 \mathrm{~cm}$ above the heart. With this preparation, which is essentially the Langendorff perfusion method, the heart continues to beat but does not perform external work.

Ischemic cardiac arrest may be produced by clamping the aortic cannula. At this time, a cardioplegic solution is infused into a side arm of the aortic cannula. During the ischemic period, the heart is maintained under hypothermia $\left(4^{\circ} \mathrm{C}\right)$ by a cooling circuit.

Chemicals. St. Thomas' Hospital cardioplegic solution No. 1, which was supplied as a concentrate (David Bull Laboratories, Mulgrave, Victoria, Australia), was diluted in Ringer's solution (Travenol Laboratories, Thetfolk, U.K.) and passed through a $0.2 \mu \mathrm{m}$ filter (Pall Biomedical, Glen Cove, N.Y.). L-Monomethylarginine (L-NMMA) (Wellcome PLC, London, U.K.), glyceryl trinitrate (GTN; David Bull) and 5-hydroxytryptamine (5-HT) (Sigma, Poole, U.K.) were diluted in Krebs solution.

Endothelial and vascular smooth muscle studies. Endothelial and vascular smooth muscle functions were assessed through observations on preischemic and postischemic coronary flow responses to 5-HT and GTN (15 $\mathrm{mg} / \mathrm{L}){ }^{12,13}$ After excision of the heart and aortic cannulation, Langendorff perfusion was initiated at $37^{\circ} \mathrm{C}$. Coronary flow was monitored by an in-line electromagnetic flow probe (ECM2 $20 \mathrm{ml}$; Scalar, Delft, Holland), proximal to the aortic cannula and connected to its compatible flowmeter (MDL 1401; Scalar). This provided an accurate $(0.0$ to $40.0 \mathrm{ml} / \mathrm{min}$ ) digital readout of mean coronary flow and simultaneous hard-copy recording (Fig. 1) through connection with a chart recorder (series 3000; Gould Electronics, Hainault, U.K.), which allowed accurate monitoring of steady-state conditions (less than 0.3 $\mathrm{ml} / \mathrm{min}$ change in coronary flow during a 3-minute period). Our protocol for this test had been determined in earlier studies. ${ }^{13}$. Inhibition of basal secretion of nitric oxide was assessed by L-NMMA $(500 \mu \mathrm{m})$, a specific inhibitor of nitric oxide secretion, as described elsewhere. $^{10}$

Experimental time course. The animals were anesthetized with halothane mixed with $95 \%$ oxygen plus $5 \%$ carbon dioxide. The femoral vein was exposed and heparin (200 IU) was injected. One minute later, the heart was excised and immediately placed in cold $\left(10^{\circ} \mathrm{C}\right)$ Krebs buffer. Approximately 30 seconds later, the aorta was cannulated and Langendorff perfusion was initiated for 10 minutes to allow steady coronary flow to be reached. In the first series ( $n=6$ in each age group), hearts were perfused with 5-HT and then washed out with Krebs buffer. This was followed by perfusion with GTN and a washout period with Krebs buffer.

The hearts were subjected to a $10 \mathrm{ml}$ hypothermic $\left(4^{\circ} \mathrm{C}\right)$ coronary infusion with St Thomas' Hospital No. 1 solution and then maintained in a state of hypothermic ischemic arrest immersed in the same solution for 4 hours at $4^{\circ} \mathrm{C}$. After the ischemic period, hearts were subjected to the same sequence of perfusion (Fig. 1). In the second series, hearts were perfused by Krebs solution and then L-NMMA, then washed out with Krebs solution during both preischemic and postischemic periods. During perfusion with any substance, steady coronary flow was allowed to be reached before further perfusion was initiated. ${ }^{13}$

Expression of results. Coronary flow was expressed in milliliters per minute. The inhibitory effect of L-NMMA was expressed as a percentage of loss of steady coronary flow. The vasodilatory responses to 5-HT and GTN were 
Table I. Influence of age on preischemic and

\begin{tabular}{cccc}
\multicolumn{4}{c}{ postischemic recovery of coronary flow } \\
\hline $\begin{array}{c}\text { Age } \\
\text { (months) }\end{array}$ & $\begin{array}{c}\text { Preischemic CF } \\
\text { (ml/min) }\end{array}$ & $\begin{array}{c}\text { Postischemic CF } \\
\text { (ml/min) }\end{array}$ & $\begin{array}{c}\text { Recovery (\% of } \\
\text { preischemic value) }\end{array}$ \\
\hline 1 & $9.4 \pm 0.8$ & $8.9 \pm 0.6^{*}$ & $94.6 \pm 1.3$ \\
5 & $12.8 \pm 1.0$ & $11.4 \pm 0.9^{*}$ & $89.4 \pm 2.0$ \\
15 & $13.5 \pm 0.7$ & $11.8 \pm 1.2 \dagger$ & $81.3 \pm 1.6$ \\
26 & $14.7 \pm 0.4$ & $11.2 \pm 1.1^{*}$ & $76.1 \pm 1.8$ \\
\hline
\end{tabular}

Each value represents the mean of six hearts \pm SEM.

A significant difference was shown between each age group and between preischemic and postischemic values in each age group. During the preischemic and postischemic periods, $p<0.05$ between each group. $C F$, Coronary flow.

${ }^{*} p<0.05$ between preischemic and postischemic periods

$\dot{t} p<0.02$ between preischemic and postischemic periods.

expressed as a percentage of change in the baseline coronary flow. Postischemic recovery of response to 5-HT and GTN was expressed as a percentage of individual preischemic control response. The postischemic recovery of coronary flow was expressed as the percentage of the preischemic value. Data were compared by analysis of variance whenever significance was indicated; Scheffe's test for multiple comparison was used for comparisons between groups. Significance was assumed when $\mathrm{p}$ was less than 0.05 . Values were given as mean \pm standard error of the mean [SEM].

\section{Results}

The influence of aging on preischemic and postischemic coronary flow is shown in Table I. The recoveries (expressed as mean percentage of the preischemic value \pm SEM) were as follows: $94.6 \% \pm 1.3 \%, 89.4 \% \pm 2.0 \%, 81.3 \% \pm 1.6 \%$, and $76.1 \% \pm 1.8 \%$ at $1,5,15$, and 26 months, respectively. A significant difference was found between each group and between the preischemic and postischemic period for each group (Table I).

The influence of age on preischemic and postischemic basal and stimulated release of nitric oxide, as assessed by the inhibitory effect of L-NMMA on coronary flow (percentage of loss of steady coronary flow) and by the vasodilatory response to 5-HT, is shown in Fig. $2(A)$. The recoveries of basal release (expressed as mean percentage of the preischemic response to L-NMMA \pm SEM) were as follows: $87.1 \% \pm 1.7 \%, 81.2 \% \pm 2.3 \%, 79.6 \% \pm 1.9 \%$, and $74.9 \% \pm 2.4 \%$ at $1,5,15$, and 26 months, respectively. The recoveries of stimulated release of nitric oxide (expressed as mean percentage of the preischemic response of coronary flow to $5-\mathrm{HT} \pm$ SEM) were as follows: $88.3 \% \pm 1.5 \%, 83.4 \% \pm$ $2.4 \%, 71.1 \% \pm 2.7 \%$, and $63.1 \% \pm 3.3 \%$ in groups $1,2,3$, and 4, respectively. Recovery of both basal and stimulated release of nitric oxide displayed a significant difference between each age group (Fig. 2,B).

Preischemic and postischemic response of coronary flow to GTN is shown in Fig. $3(A)$. The recoveries of vascular smooth muscle function (expressed as mean percentage of the preischemic response of coronary flow to GTN) were as follows: $96.7 \% \pm 2.1 \%, 92.3 \% \pm 5.2 \%, 92.9 \% \pm 5.0 \%$, and $98.1 \% \pm 2.4 \%$ (Fig. 3, $B$ ). No significant difference was found between each age group ( $p=$ not significant).

\section{Discussion}

This study showed that after prolonged cardioplegic arrest the capacity to recover coronary flow, as well as the basal and stimulated release of nitric oxide, decreases with age. In contrast, the postischemic recovery of vascular smooth muscle function is not altered with age.

The aging process is known to induce profound physiologic, ultrastructural, and biochemical alterations in the cardiac myocyte. These include decreased activity of the calcium pump, ${ }^{3,4}$ impairment of the coupling of receptors to adenylate cyclase, ${ }^{5}$ reduction of the fast isoform of myosin, ${ }^{6}$ and a diminution in high-energy phosphate levels. ${ }^{7}$ These changes could explain the differential susceptibility of mechanical function to ischemia with aging. ${ }^{2}$

During the last decade, coronary endothelial cells have been found to play a major role in cardiac homeostasis because of their ability to secrete various vasoactive substances, ${ }^{8}$ including nitric oxide. ${ }^{9}$ Basal secretion of nitric oxide is known to be of crucial importance in the maintenance of cardiac contractility. ${ }^{10}$

In this study, we found that endothelial function, reflected by basal and stimulated release of nitric oxide, showed age-dependent vulnerability to ischemia. We examined the effect of L-NMMA, an inhibitor of the production of nitric oxide from L-arginine, on basal coronary flow. We also investigated the effect of release of nitric oxide stimulated by 5-HT on steady coronary flow. Postischemic recovery of basal release of nitric oxide dropped significantly, from $87 \%$ in the young age group to $79 \%$ in the middle-aged animals and $74 \%$ in the old age group. The same trend was followed by the stimulated release of nitric oxide: the postischemic recovery was reduced from $88 \%$ in the young age group to $71 \%$ in the middle-aged group, and it dropped further to $63 \%$ in the oldest group. The cause of this age-related change in the capacity of 
A

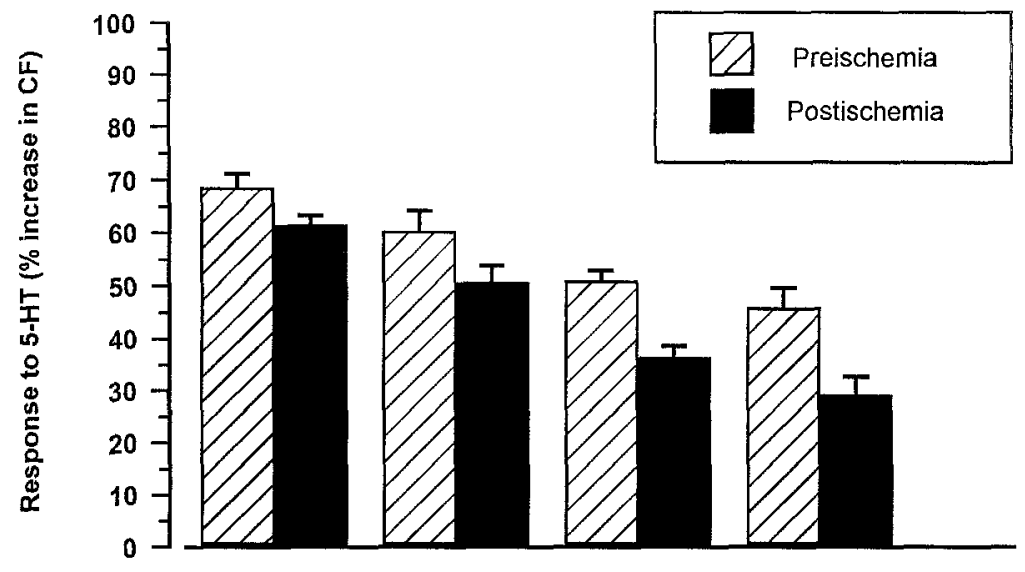

1 month 5 months 15 months 26 months AGE
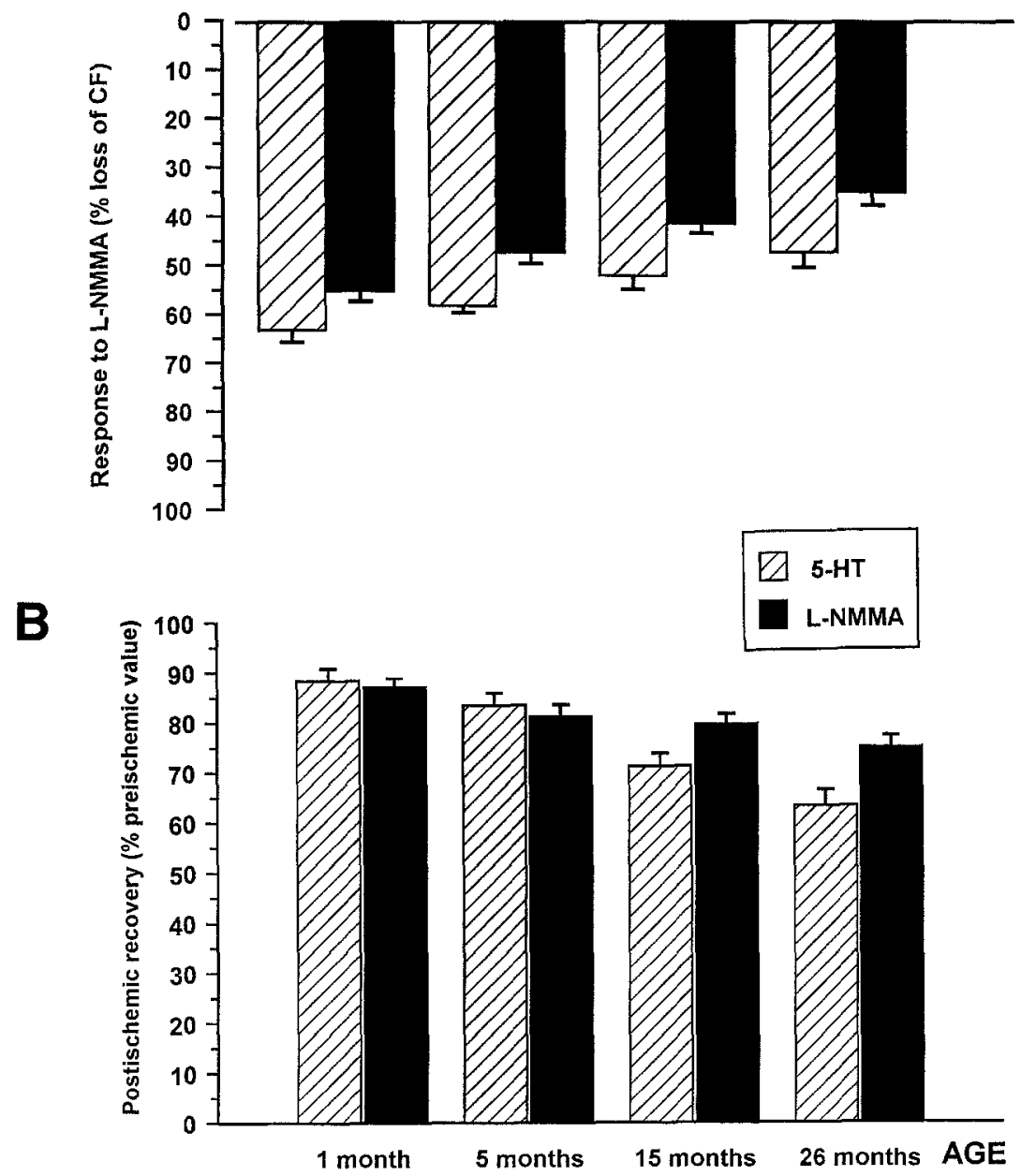

Fig. 2. A, Influence of age on preischemic and postischemic responses to 5-HT and to L-NMMA. Each bar represents the mean of six hearts \pm SEM. Between each age group, $p<0.05$, and $p<0.05$ between preischemic (hatched bars) and postischemic (black bars) values in each age group. B, Influence of age on postischemic recovery of coronary response to 5-HT (hatched bars) and to L-NMMA (black bars). Each bar represents the mean of six hearts $\pm \mathrm{SEM}$. Between each age group, $p<0.05$, except between groups 1 and $4(p<0.02)$. $C F$, Coronary flow. 


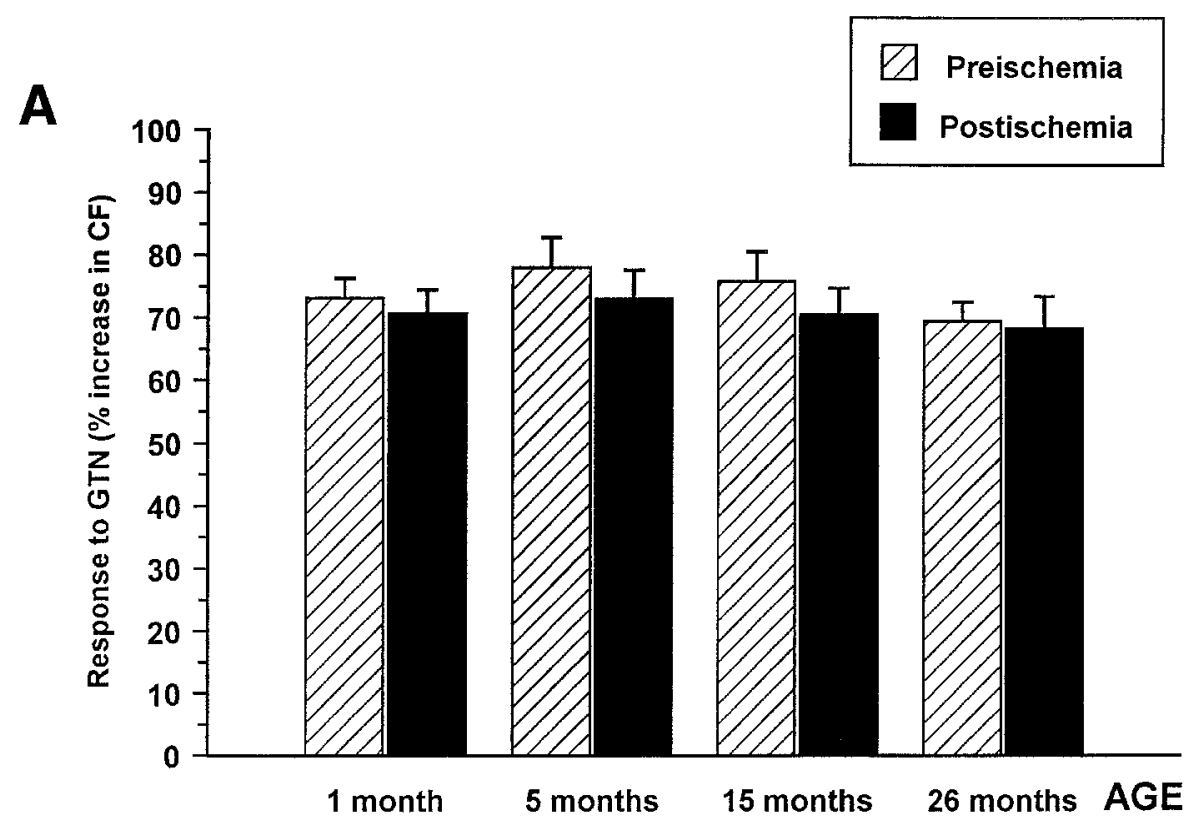

B

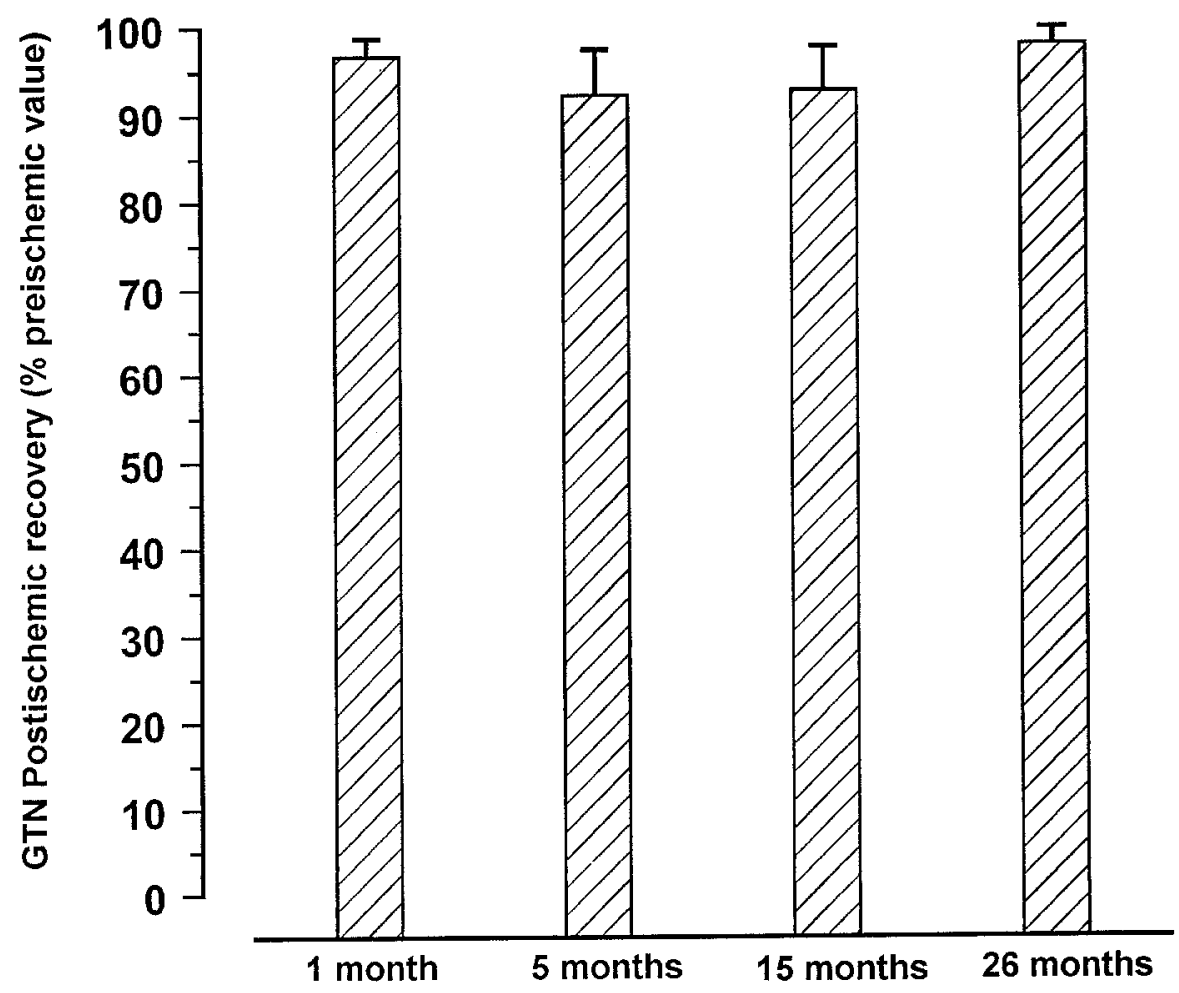

Fig. 3. A. Effect of age on preischemic and postischemic coronary responses to GTN. Each bar represents the mean of six hearts \pm SEM. Between each age group, $p$ was not significant, and $p$ was also not significant between preischemic (hatched bar) and postischemic (black bar) values in each age group. B, Effect of age on postischemic recovery of coronary response to GTN. Between each age group, $p$ was not significant. $C F$, Coronary flow. 
endothelial cells for recovery of endothelial function after ischemia is not known.

This change could be caused by functional or structural alterations. The latter is unlikely to be the cause because the vasodilatory response to $5-\mathrm{HT}$ is known to occur only when endothelial cells are morphologically intact. ${ }^{12}$ In the presence of endothelial damage, 5-HT causes vasoconstriction by direct effect on smooth-muscle 5-HT receptors. This effect was not observed in any of the hearts examined in this study. In addition, potential mechanisms involving platelets or leukocyte interactions can be ruled out in the asanguineous model we used. The observed increased susceptibility of endothelial function to ischemia with age is therefore most probably caused by functional cellular disturbances that lead to a reduced capacity of endothelial cells for secretion of nitric oxide with age.

Superoxide anion generated after ischemia is known to reduce nitric oxide. ${ }^{14}$ More recently, in vitro studies have shown that oxygen free radicals selectively alter receptor-dependent nitric oxide production by the coronary endothelium. ${ }^{15}$ In addition, aging is known to be associated with a decreased capacity for scavenging of free radicals. ${ }^{16}$ This age-dependent susceptibility to free radicals has even been advocated as one of the main mechanisms of the aging process. ${ }^{17}$ Moreover, endothelial cells are thought to be an important site of production of oxygen free radicals through xanthine oxidase catalyzed-reactions. ${ }^{18}$ The reduction of free-radical scavengers with aging, combined with the ischemia and reperfusion-induced production of free radicals, could therefore explain the age-related vulnerability of endothelial function after ischemia.

The vascular smooth muscle function did not display any modification at different animal ages. Our findings suggest that recovery of the contractile machinery after prolonged cardioplegic arrest is not modified by aging.

We observed that low coronary reflow was more marked in the older animals, a difference probably related to the measured lower basal secretion of nitric oxide in these animals. The crucial role of nitric oxide in cardiac mechanical function ${ }^{10}$ and the importance of low reflow on the postischemic recovery of mechanical function have been shown previously. ${ }^{19}$ Age-related differences in tolerance to ischemia of mechanical function have been reported in numerous studies. ${ }^{2,7,20}$ From most of the experimental data, it appears that neonatal hearts are more resistant to ischemia. This resistance has been attributed chiefly to greater potential for glycolytic flux ${ }^{21}$ and to reduced calcium transport dysfunction. $^{3,4}$ In addition, it has been shown that the enzyme 5 '-nucleotidase, which plays a predominant role in the degradation of adenosine triphosphate during ischemia in adult heart, is relatively deficient in the immature heart. ${ }^{22,23}$ This deficiency would confer a natural protection by reducing the loss of high-energy substrates and by reducing free radicalmediated injury because the terminal compounds of the breakdown of adenosine triphosphate are substrates for xanthine oxidase. This latter mechanism is of particular relevance for the postischemic recovery of endothelial function, in which xanthine-oxidase plays a crucial role. ${ }^{18,24}$

Other studies have demonstrated from function$\mathrm{al}^{25}$ biochemical, ${ }^{26}$ and anatomic ${ }^{27}$ data, however, that immature hearts are actually more vulnerable to ischemia. The lack of uniformity in the experimental protocols (species, temperature of preservation, length of ischemia, volume of cardioplegia, crystalloid or blood perfusion model) could explain this discrepancy. The exact age ranges studied could also be of paramount importance. Indeed, early after birth, as the number of mitochondria increases, the dependence of the immature heart on anaerobic metabolism lessens. ${ }^{28}$ This "critical moment" could vary from species to species and could also apply to the deficiency in $5^{\prime}$-nucleotidase activity. Lack of precision in the definition of experimental age groups could therefore lead to dramatic differences in the interpretation of results.

Our study was performed in an asanguineous model. Although this has the advantage of avoiding the confounding factors of the effects of blood elements and cardiopulmonary bypass, it has its own limitations. These include the fact that there is maximal vasodilatation in this model, and it could be argued that this state does not reflect the global situation that occurs in the clinical setting, which could be complex. Vasoconstricting agents are released from several sources during cardiopulmonary bypass. Platelet activation during extracorporeal circulation induces the release of serotonin and thromboxane $A_{2}$ into the plasma. ${ }^{29}$ Although vasodilating agents such as prostacyclin and prostaglandin $E_{2}$ are also released during cardiopulmonary bypass, the level falls later when some blood passes through the lung. ${ }^{30}$ In addition, thromboxane $A_{2}$ reaches peak levels as the lungs are perfused. The final tendency would be toward vasoconstriction. Moreover, hemolysis during cardiopulmonary bypass generates free 
hemoglobin. ${ }^{31}$ Free hemoglobin is known to be a potent inactivator of nitric oxide..$^{32}$ Furthermore, complement activation is initiated by the contact of plasma with the foreign surface and leads to the production of powerful anaphylatoxins (C3a and C5a), which increase vascular permeability, cause smooth muscle contraction, mediate leukocyte chemotaxis, and facilitate neutrophil aggregation. ${ }^{33,34}$ Activated neutrophils are important sources of free radicals, ${ }^{35}$ which are known to inactivate nitric oxide. ${ }^{14}$

In conclusion, our study has shown an age-related vulnerability of endothelial function after prolonged cardioplegic arrest. In light of our previous work, ${ }^{10}$ we believe that this could be another mechanism through which the resistance of cardiac contractility to ischemia is reduced by age. Consideration of this mechanism could have important physiologic and possibly therapeutic implications.

We thank Mr. A. J. Amrani for his help with the statistical analysis.

\section{REFERENCES}

1. Muscari C, Caldarera I, Rapezzi C, Branzi A, Caldarera CM. Biochemical correlates with myocardial aging. Cardioscience 1992;3:67-75.

2. Bove EL, Stammers AH. Recovery of left ventricular function after hypothermic global ischemia: age-related differences in the isolated working rabbit heart. J Thorac Cardiovasc Surg 1986;91:115-22.

3. Narayanan N. Differential alterations in ATP-supported calcium transport activities in sarcoplasmic reticulum and sarcolemma of aging myocardium. Biochem Biophys Acta 1981;678:442-59.

4. Tate CA, Taffet GE, Hudson EK, Blaylock CL, Mobride RP, Michael LH. Enhanced calcium uptake of cardiac sarcoplasmic reticulum in exercise-trained old rats. Am J Physiol 1990;258:H431-5.

5. O'Connor SW, Scarpace JP, Abrass IB. Age-associated decrease of adenylate cyclase activity in rat myocardium. Mech Ageing Dev 1981;16:91-5.

6. Whalen RG, Sell SM, Eriksson A, Thornell LE. Myosin subunit types in skeletal and cardiac tissues and their developmental distribution. Dev Biol 1982; 91:478-84.

7. Jullien T, Cand F, Fargier C, Verdetti J. Age-dependent differences in energetic status, electrical and mechanical performance of rat myocardium. Mech Ageing Dev 1989;48:243-54.

8. Vanhoutte PM, Houston DS. Platelets, endothelium and vasospasm. Circulation 1985;72:728-34.

9. Palmer RM, Ashton DS, Moncada S. Vascular endothelial cells synthesize nitric oxide from $\mathrm{L}$-arginine. Nature 1988;333:664-6.

10. Amrani M, O'Shea J, Allen NJ, et al. Role of basal release of nitric oxide on coronary flow and mechanical performance of the isolated rat heart. J Physiol 1992;456:681-7.

11. Hearse D, Stewart D, Braimbridge M. Cellular protection during myocardial ischemia: a development in characterization of a procedure for the induction of reversible ischemic arrest. Circulation 1967;54:193202.

12. Saldanha C, Hearse DJ. Coronary vascular responsiveness to 5-hydroxytryptamine before and after infusion of hyperkalemic crystalloid cardioplegic solution in the rat heart. J THorac Cardiovasc Surg 1989;98:783-7.

13. Amrani M, Ledingham S, Jayakumar J, et al. Detrimental effects of temperature on the efficacy of the University of Wisconsin solution when used for cardioplegia at moderate hypothermia: comparison with the St. Thomas' Hospital solution at $4^{\circ} \mathrm{C}$ and $20^{\circ} \mathrm{C}$. Circulation 1992;86(Suppl 2):286-8.

14. Rubanyi GM, Vanhoutte PM. Superoxide anion and hypoxia inactivate endothelium-derived relaxing factor. Am J Physiol 1986;250:H822-7.

15. Seccombe JF, Pearson PJ, Schaff HV. Oxygen radicalmediated vascular injury selectively inhibits receptordependent release of nitric oxide from canine coronary arteries. J THORAC CARDIOVASC SURG 1994;107: 505-9.

16. Sohal RS, Sohal BH, Brunk UT. Relationship between antioxidant defenses and longevity in different mammalian species. Mech Ageing Dev 1990;53:21727.

17. Sawada M, Carlson JC. Changes in superoxide radical and lipid peroxide formation in the brain, heart and liver during the lifetime of the rat. Mech Ageing Dev 1987;41:125-37.

18. Ambrosio G, Weisfeldt ML, Jacobus WE, Flaherty JT. Evidence for a reversible oxygen radical-mediated component of reperfusion injury: reduction by recombinant human superoxide dismutase administered at the time of reflow. Circulation 1987;75:282-91.

19. Amrani M, Shirvani R, Allen NJ, Ledingham S, Yacoub MH. Enhancement of low coronary reflow improves postischemic myocardial function. J THORAC CARdiovasc Surg 1992;104:1375-82.

20. Baker JE, Borboom LE, Olinger GN. Age-related changes in the ability of hypothermia and cardioplegia to protect ischemic rabbit myocardium. J THORAC CARDIOVASC SuRg 1988;96:17-24.

21. Hoerter JA, Mazet F, Vassot G. Perinatal growth of the cardiac rabbit cell: possible implications for the mechanism of relaxation. J Mol Cell Cardiol 1981;18: $725-40$.

22. Grosso MA, Banerjee A, St Cyr JA, et al. Cardiac 5 -nucleotidase activity increases with age and inversely relates to recovery from ischemia. J THORAC CARDIOVASC SURG 1992;103:206-9. 
23. Pridjian AK, Bove EL, Bolling SF, Childs KF, Brosamer KM, Lupinetti FM. Developmental differences in myocardial protection in response to $5^{\prime}$-nucleotidase inhibition. J Thorac Cardiovasc Surg 1994; 107:520-6.

24. Lawson DL, Mehta JL, Nichols WW. Coronary reperfusion in dogs inhibits endothelium-dependant relaxation: role of superoxide radicals. Free Radic Biol Med 1990;8:373-80.

25. Magovern JA, Pae WE, Waldhausen JA. Protection of the immature myocardium. An experimental evaluation of topical cooling, single-dose, and multipledose administration of St. Thomas' Hospital cardioplegic solution. J ThoraC CardiovasC Surg 1988; 96:408-13.

26. Smolenski RT, Swierczyński J, Narkiewiewicz M, Zydowo MM. Purines, lactate and phosphate release from child and adult heart during cardioplegic arrest. Clin Chim Acta 1990;192:155-63.

27. Ganzel BI, Katzmark SL, Mavroudis C. Myocardial preservation in the neonate. Beneficial effect of cardioplegia and systemic hypothermia on piglets undergoing cardiopulmonary bypass and myocardial ischemia. J Thorac Cardiovasc Surg 1988;96:414-22.

28. Hoerter JA, Opie LH. Perinatal changes in glycolytic function in response to hypoxia in the incubated or perfused rat heart. Biol Neonate 1978;33:144-61.

29. Mammen EF, Koets $\mathrm{MH}$, Washington $\mathrm{BC}$, et al.
Hemostasis changes during cardiopulmonary bypass surgery. Semin Thromb Hemost 1985;11:282-92.

30. Faymonville ME, Deby-Dupony G, Larbuisson R, et al. Prostaglandin $E_{2}$, prostacyclin, and thromboxane changes during nonpulsatile cardiopulmonary bypass in humans. J Thorac Cardiovasc Surg 1986;91:85866.

31. Martin W, Villani GM, Jothianandan D, Furchgott RF. Selective blockade of endothelium-dependent and glyceryl trinitrate-induced relaxation by hemoglobin and methylene blue in the rabbit aorta. J Pharmacol Exp Ther 1985;232:708-16.

32. Salama A, Hugo F, Heinrich D, et al. Deposition of terminal C5b-9 complement complexes on erythrocytes and leukocytes during cardiopulmonary bypass. N Engl J Med 1988;318:408-11.

33. Cavarocchi NC, Schaff HV, Orszulak TA, Homburger HA, Schnell WA, Pluth JR. Evidence for complement activation by protamine-heparin interaction after cardiopulmonary bypass. Surgery 1985;98:525-31.

34. Cavarocchi NC, Pluth JR, Schaff HV, et al. Complement activation during cardiopulmonary bypass: comparison of bubble and membrane oxygenators. J THORAC CARDIOVASC SURG 1986;91:252-8.

35. Cavarocchi NC, England MD, Schaff $\mathrm{HV}$, et al. Oxygen free radical generation during cardiopulmonary bypass: correlation with complement activation. Circulation 1986;74(5 Pt 2):III130-3. 